\title{
Effects of Service Value on Attitude, and Loyalty in Food-Service Franchise

$$
\begin{gathered}
\text { 외식프랜차이즈의 서비스 가치가 인지적 태도, 정서적 태도, 그리고 } \\
\text { 충성도에 미치는 영향 }
\end{gathered}
$$

\author{
Shin-Hwa LEE(이신화)*, Yong-Ki LEE(이용기)**, Jae-Gyu LEE(이재규)***
}

Received: August 20 2019. Revised: September 02, 2019. Accepted: September 10, 2019.

\begin{abstract}
Purpose - The recent franchise industry is rapidly developing. Some franchisees have a low barriers to entry and competition among companies is intensifying. In this dynamic competitive environment, companies need to focus on customer preferences, quality, and technical interfaces to gain competitive advantage. As a result, companies are required to measure the performance of service values in order to provide differentiated services from competitors. In the franchise industry, customer experience marketing of service values will enable companies to create new businesses. Franchise firms should explore a variety of services to increase service value and reduce failures.

Research design, data, methodology - The questionnaire of this study was based on the previous research. Surveys were conducted on panels of online surveys. Surveys were conducted on the panel who had visited the restaurant franchise within the past month. The survey was conducted for about 7 days from February 13, 2019 to February 19, 2019. Total 300 samples, 293 were used in the analysis except for seven unfair questionnaires.

Results - The findings of this study are as follows: Emotional, monetary, and reputation values have positive effects on cognitive and affective attitudes. Quality value and behavioral value did not effect cognitive attitude and affective attitude significantly. In addition, affective attitude has positive effect on loyalty, but cognitive attitude did not significant effect on loyalty.

Conclusions - First, food-service franchise company should develop a service that enables customers to use the store conveniently. We need to develop a comfortable environment for our customers and provide intangible services. Second, food-service franchise company should provide a reasonable price service. Food-service franchise company needs to sell a high quality menu at a reasonable price to generate profits. Third, food-service franchise companies need to strategically respond to their reputation. In other words, food-service franchise company needs to constantly monitor the reputation of its customers and respond appropriately to market conditions. Fourth, food-service franchise company needs to develop a service method capable of emotional interaction with customers. Food-service franchise firms need to develop ongoing service methods and educate their staff.
\end{abstract}

Keywords: Service value, Cognitive attitude, Affective attitude, Loyalty, Food-service franchise.

JEL Classifications: L83, M10, M31.

* First author, Doctoral Candidate, CEO, Cheungdam Shinhwa Commerce Group, Seoul Korea, Email: ceoshgroup@gmail.com

** Coauthor, Professor, School of Business, Sejong University, Seoul, Korea, Email: yongki2@sejong.ac.kr

*** Corresponding author, Adjunct Professor, Department of Hotel \& Restaurant Management, Shin Ansan University, Gyeonggi Province, Korea. Tel: +82-31-490-8910, Email: overkill38@hanmail.net 


\section{1. 서론}

최근의 프랜차이즈 산업은 급속히 발전하고 있다. 일부 프랜차이즈 분 야는 진입장벽이 낮아 기업 간 경쟁이 치 열해 지고 있다. 이러한 역동적인 경쟁 환경에서 기업은 경쟁력을 확보하기 위해 고 객의 선호도, 품질, 그리고 기 술적인 인 터 페이스를 고 객 중심으로 초점을 맞추어 변화시켜야 한다 (Karmarkar, 2004).

외식프랜차이즈의 서비스와 메뉴는 쉽게 모방이 가 능하기 때문에, 유사한 유형의 기업이 지속적으로 발생하고 있다. 이 러한 상황은 경쟁사와 차별화된 서비스를 제공하려고 할 때, 어려움을 줄 수 있다(Reid \& Sandler, 1992). 고객의 기대와 성과를 비 교하는 서비스 품질은 마케팅 및 외식 서비스 연 구에서 중요하게 다 루어지고 있다 (Parasuraman, Zeithaml \& Berry, 1988). 초기의 서비스 품질은 고 객이 서비스 품질을 인식하는 방 법과 그 인식을 측정하는 방 법이 연구되었다 (Grönroos, 1984). 따라서 기업은 경쟁사와 차별 화된 서비스 를 제공하기 위해 서비스 가치를 측정해야 한다. Zeithaml (1988)은 지각된 가치가 품질, 가격(금전 및 비금전적), 제품 또는 서비스의 평판 그리고 제품 또는 서비스에 대한 감정 (감정적 반 응)으로 구성되어 있다고 하였다.

외식프랜차이즈 산업의 이러한 어려움을 극복하기 위해 외식프랜차이즈 기업은 고 객에게 혁신적인 서비스 가치를 지속적으로 제공해야 한다. 서비스는 가치 있는 무형의 상품 으로 외식프랜차이즈 기업의 서비스 마케팅은 기업 성과 형 성에 중요한 요소이다(Pine \& Gilmore, 1998). 프랜차이즈 산업에서 서비스에 대한 고 객의 체험 마케팅은 기업에게 새 로운 성과를 창출할 수 있게 해 줄 것이다.

고객에게 양 질의 서비스 제공은 기업이 지속 가 능하고 경 쟁 우위를 확보할 수 있으며, 기업의 성과에 긍정적인 영향 을 미 친다(Fornell, Mithas, Morgeson III, \& Krishnan, 2006). 외식프랜차이즈와 같은 서비스 제공 기업의 성과는 고 객 중심 서비스를 제공할 수 있는 능력에 따라 달라진다(Gustafsson \& Johnson, 2003). 즉, 서비스 제공 기업은 반 복된 서비스 실패는 낮은 성과를 나타 낼 수도 있다(Meyer \& Schwager, 2007). 외식프랜차이즈 기업은 서비스 가치를 높이고 실패 를 줄이기 위해 다양한 서비스를 모색하고 있다.

서비스에 대한 연구는 마케팅 분야와 함께 발전하고 있다 (Vargo \& Lusch, 2008). 서비스 분 야에서 다양한 관점의 고 객 가치에 대한 연구가 진행되고 왔다(Lin, Sher, \& Shih, 2005; Petrick, 2002; Ruiz, Gremler, Washburn, \& Carrión, 2008; Sánchez-Fernández, Iniesta-Bonillo, \& Holbrook, 2006). 이러한 가치는 태도와 행동 의도 형성을 유도하는 척도 로 이용되고 있다(Honkanen, Verplanken, \& Olsen, 2006).

서비스에 대한 연구는 고 객 충성도 향상을 위해 다양하게 연구되고 있다(De Ruyter, Bloemer, \& Peeters 1997). Cronin and Taylor(1992)는 고 객의 서비스 인식이 고 객 충성 도 형성에 중요한 영향을 미 친다고 하였다. 외식프랜차이즈 기업의 성장을 위한 핵심 성공요인은 고 객 기반의 높은 서 비스를 고 객에게 제공해야 고객이 만족하고 결과적으로 고 객 가치가 확보된다.

따라서 본 연구에서는 서비스 가치를 품질 가치, 감정적
가치, 경제적 가치, 행동적 가치, 그리고 평판 가치로 구분 한 Zeithaml(1988)의 연구를 바탕으로 외식프랜차이즈의 서 비스 가치가 인지적 태도, 정서적 태도, 그리고 충성도에 미 치는 영향에 대해 연구하고자 한다.

\section{2. 이론적 배경}

\section{1. 서비스 가치}

지각된 가치에 대한 정의가 다양하게 연구되고 있지만 (Dodds \& Monroe, 1991; Sheth, Newman, \& Gross, 1991), 가장 보 편적인 정의는 고 객이 받는 것에 대한 인식과 주는 것에 대한 인식에 기초한 제 품의 유용성에 대한 전반적인 평가이다(Zeithaml, 1988). 즉, 가치는 활동에서 얻는 개인적 인 평가이다(Lai, Griffin, \& Babin, 2009). 기업이 제 품 또는 서비스를 변경하거나, 경쟁사가 하는 제 품 또는 서비스를 변 경하거나, 소비자의 욕구 또는 필요가 바뀌면 지각된 가치가 변할 수 있다.

Zeithaml(1988)은 서비스 가치를 개 념화 하기 위한 기반 을 마련하였다. Zeithaml(1988)은 고 객이 제 품 또는 서비스 가격과 품질에 대한 가치 인식에 대해 연구하였다. 그의 연 구에서 제 품 또는 서비스 속성으로 구성된 지각된 품질이 지각된 가치로 이어진다고 하였다. 지각된 가치는 고 객이 얻 는 것(품질, 혜택, 유용성)과 제 품 구매 및 소비에 대한 포기 (가격, 희생, 시간) 사이의 절충이다. 다른 Petrick and Backman(2002)의 연구에서는 SERV-PERVAL 척도를 바탕 으로 서비스 가치를 품질, 경제적, 행동적, 평판 및 감정적 가치의 다섯 가지 차원으로 구성하였다. 지각된 가치에 대한 연구는 대부분 고 객이 인지하는 가치에 대해 정의하고 서비 스 구성 요소를 반영한 연구는 거의 없었다(Ruiz, Gremler, Washburn, \& Carrión, 2008). 서비스 가치에 대한 연구는 기존의 제 품 중심 마케팅 접근 방식에서 서비스 기반 마케 팅으로 전 환되고 있다(Vargo \& Lusch, 2008).

가치는 가 격뿐만 아니라 내적 특성(구매에 대한 느낌) 및 외적 특성(제품 또는 서비스의 평판)은 인식 품질과 긍정적 인 관계가 있다 (Zeithaml, 1988). Zeithaml(1988)은 지각된 가치가 품질, 가격(금전 및 비금전적), 제품 또는 서비스의 평판 그리고 제품 또는 서비스에 대한 감정(감정적 반 응)으 로 구성되어 있다고 하였다.

$\mathrm{Hu}$, Kandampully, and Juwaheer(2009)는 지각된 가치를 제품 또는 서비스의 품질과 가 격과의 관계로 설명하였다. Bojanic(1996)은 가격 기반 상대적 지각된 가치를 비슷한 가 격으로 비 슷한 품질 제공, 프리미엄 가격으로 우수한 품질 제공, 그리고 저렴한 가격으로 낮은 품질 제공의 세 가지 포 지션으로 구성된다고 하였다. 기업은 고 객의 행동에 영향을 미치는 제 품 또는 서비스에 대한 고객의 상대적 지각된 가 치를 통해 경쟁우위를 확보한다. 상대적 지각된 가치는 경쟁 제품과 비교하여 제품 또는 서비스를 통해 받는 가치이다.

외식프랜차이즈는 식사뿐만 아니라 매장 이용에 즐거움과 행복감 같은 감정적인 혜택을 가지고 있다. 많은 소비자가 
감정적 욕구를 충족시키기 위해 제품 또는 서비스를 구매한 다(Kumar, Lee, \& Kim, 2009). 감정적 가치는 제 품이나 서 비스에 대한 감정이나 정서적으로 유 익한 혜택으로 정의된 다(Sweeney \& Soutar, 2001). Bagozzi, Gopinath, and Nyer (1999)는 감정적 가치를 기업과 소비자와의 관계에 대한 반 응으로 형성되는 소비 감정이라고 하였다. 이러한 감정적 가 치는 구매의도에 긍정적인 영향을 미치는 것으로 나타났다 (Dodds, Monroe, \& Grewal, 1991).

Parasuraman and Grewal(2000)은 지각된 가치가 취 득 가치, 거래 가치, 사용 가치 그리고 보상 가치의 네 가지 유 형으로 구성된다고 하였다. 그들은 취 득 가치는 금전적인 가 격에 대해 얻은 이 익이며, 거래 가치는 좋은 거래를 얻기 위 해 소비자가 받는 즐거움으로 정의하였다.

많은 고 객은 독립된 외식 브랜드를 기 억하는데 어려움을 격고 있으며, 알려지지 않는 외식 업체 방문을 꺼려한다. 따 라서 평판은 외식프랜차이즈에 대한 고 객의 지각된 가치가 될 수 있다. 기업의 평판은 기업에 대한 고 객의 과거 경험 (Weigelt \& Camerer, 1988)과 직접 또는 간접인 경험과 정 보를 받음으로서 형성된다(Ruth \& York, 2004). Eberl and Schwaiger(2005)는 평판이 기업에 대한 고 객의 전반적인 정 서적 평가라고 하였다.

\section{2. 태도}

태도는 대상 , 사건 또는 자 극에 대해 일 관되게 호의적이 거나 바람직하지 않은 방식으로 반 응하는 학습된 경향을 의 미한다(Fishbein \& Ajzen, 1975). Birgelen, Ruyter, and Wetzels(2003)는 태도를 대상에 대해 어 느 정도의 호의 또 는 불만으로 평가함으로써 표현되는 심리적 경향으로 정의 하였다. Malhotra(2005)는 태도를 대상에 대한 평가의 요약 으로 정의하였으며, 신념은 태도 형성에 매우 중요하다고 하 였다. 이러한 정의에 따르면 태도는 대상에 대한 경험이나 다른 정보에 의해 형성된 지식에 따라 태도가 발전할 수 있 다는 의미이다. 소비자의 태도와 구매 의도 또는 구매 행동 간에 유의한 관계가 있다(Simester, 2016). 대부분의 연구에 서 태도는 행동의도와 긍정적 관계가 있는 것으로 나타났다 (Zhang, \& Kim, 2013).

사람들은 서비스나 브랜드에 대해 그들이 믿는 것과 어떻 게 생각하는지를 통해 태도를 측정한다(Farris, Bendle, Pfeifer, \& Reibstein, 2010). Abdul-Muhmin(2010)은 긍정적 인 반 응과 부정적인 반 응이 태도에 반영될 수 있다고 하였 다.

태도는 다양한 분 야에서 다양한 상황으로 사용되어 왔다 (Moon, Khalid, Awan, Attiq, Rasool, \& Kiran, 2017). 태도는 단일 차원의 구조(Sallam \& Wahid, 2012)가 아니라 인지, 감정, 감정, 가치, 그리고 의식 등 다양한 차원으로 구성되 어 있다(Fiore \& Kim, 2007). 그러나 일반적으로 태도는 단 일 차원 또는 인지적, 정서적 그리고 행동적으로 구분하여 연구되고 있다(Hasan, 2010). 인지적 태도와 정서적 태도는 행동적 태도에 영향을 미 친다(Hasan, 2010). 행동적 태도는 무언가를 하려는 고 객의 의도가 포함된다(Chudry, Foxall, \&
Pallister, 2011). 즉, 행동적 태도는 행동의도라고 이해할 수 있다.

인지적 태도는 고 객이 대상에 대해 가지고 있는 신 념을 기반으로(Hasan, 2010) 개인이 그 대상에 의해 수행되는 유 용성과 기 능에 기초하여 대상을 좋아하거나 싫어하는 정도 를 의미한다(Celebi, 2015; Fiore \& Kim, 2007). 즉, 인지적 태도는 대상에 대한 개인의 인지적 평가로(Shih, Lai, \& Cheng, 2013) 외식프랜차이즈에 대해 아는 정도라고 할 수 있다.

인지적 태도와 정서적 태도는 서로 반대 방향으로 진행된 다. 즉, 처리 자원이 적다면 고 객은 정서적 반 응을 사용하는 경향이 더 높지만 처리 자원이 많으면 사 람들은 인지적 반 응을 선호한다. Malhotra(2005)는 사 람들은 인지 과정을 통 제 할 수 있으며, 이 과정이 처리 자원의 이용 가 능성에 영 향을 받는다고 하였다.

인지적 태도도 중요하지만, 점점 더 많은 연구들이 정서 적 태도가 행동의도에 미치는 영향의 중요성을 강조하고 있 다(Lawton, Conner, \& McEachan, 2009). 일부 연구에서 정 서적 태도가 인지적 태도보다 행동 예 측에 더 강한 영향을 미치는 것으로 연구되고 있다(Glasman \& Albarracin, 2006; Kraft, Rise, Sutton \& Roysamb, 2005; Trafimow, Sheeran, Lombardo, Finlay, Brown, \& Armitage, 2004).

정서적 태도는 대상을 사용하거나 경험 함으로써 얻은 감 정과 정서적 경험을 의미한다(Fiore \& Kim, 2007). 이러한 정서적 태도는 쾌락적 감정(즐거움, 흥분)으로 묘사된다 (Giner-Sorolla, 2001). 정서적 태도는 대상에 대한 고 객의 감정이며(Desai, K \& Mahajan, 1998), 외부 자 극에 의해 영 향을 덜 받는다(Malhotra, 2005).

\section{3. 충성도}

고객 충성도의 개 념은 서로 다른 시각으로 인해 복잡하게 이루어져 있다(Majumdar, 2005). 충성도의 일반적인 정의는 재 구매를 촉진하는 방식으로 제 품이나 서비스를 재구매하 겠다는 약속이다. 충성도가 높은 고 객은 가 능할 때마다 동일 한 서비스를 재구매하고, 추천하며, 이들에 대해 긍정적인 태도를 유지한다(Kandampully \& Suhartanto, 2000).

선행연구에 따르면 충성도에는 행동적 충성도와 태도적 충성도의 두 가지 종류가 있다(Baloglu, 2002; Cheng, 2011). 태도 충성도는 제 품 또는 서비스에 대한 소비자의 충성도를 구성하는 다양한 감정과 같은 개인적인 태도이다. 고객이 재 구매하지 않고 다른 고객에게 공 급 업체의 서비스를 추천하 는 경우에도 태도 충성도라고 할 수 있다 (Kursunluoglu, 2011). 태도 충성도는 공 급 업체에 대한 고객의 선호도, 구 매 의도 및 제3자에 대한 추 천을 나타 낸다. 태도 충성도는 고객이 제 품이나 서비스를 구매하는 것을 약속하지 않는다. 그러나 구전은 비즈니스의 긍정적 이미지 창출에 기여한다.

행동 충성도는 실제적 구조이지만, 태도 충성도는 심리적 구조이다(Cheng, 2011). 많은 연구는 태도 충성도와 행동 충 성도 간의 긍정적인 관계를 나타낸다(Baldinger \& Rubinson, 1996; Dick, \& Basu, 1994). 고객이 서비스 제공에 대한 강 
한 개입을 경험하면 정보를 찾는 데 시간의 일부를 사용하 는 경향이 있다(Beatty, Homer, \& Kahle, 1988). 서비스가 고객을 만족시킨다면 구매 빈도는 증가하지만 대안 검색에 대한 감소가 발생한다(Yang, Liu, Jing, \& Li, 2014).

\section{3. 연구설계}

\section{1. 연구가설}

본 연구는 외식프랜차이즈에 대한 서비스 가치가 인지적 태도와 정서적 태도에 영향을 미치고, 인지적 태도와 정서적 태도가 충성도에 미치는 영향을 파악하기 위해 다음과 같은 선행연구를 바탕으로 연구 가설을 구성하였다.

\subsection{1. 외식프랜차이즈의 서비스 가치와 태도 간의 관계}

가치는 다양한 행동 (Vaske \& Donnelly, 1999), 소비자의 의사결정 프로세스(Vermeir \& Verbeke, 2006), 그리고 다양 한 정서적 강도와 태도(Schwartz, 1994)에 영향을 미치기 때 문에 중요하다. 가치-태도-행동 모델은 행동 의도를 이해하 기 위해 사용되고 있다 (Honkanen, Verplanken, \& Olsen, 2006). 가치는 태도를 통해 간접적으로 행동에 영향을 미치 는 인지적 계층 구조로 구성되어 있다(Tudoran, Olsen, \& Dopico, 2009). Keng and Ting(2009)은 미적, 서비스 우수 성, 그리고 즐거움이 포함된 경험적 가치가 태도에 긍정적인 영향을 미친다고 하였다.

가치는 판단, 선호, 및 선택의 기준이 된다(Williams, 1979). 고객의 수용 및 태도는 고 객의 경험으로 부 터 형성 된 가치에 의해 영향을 받는다(Nambisan \& Baron, 2007). Keng, Huang, Zheng, and $\mathrm{Hsu(2007)는} \mathrm{경험적} \mathrm{가치가} \mathrm{사용}$ 태도에 긍정적 영향을 미친다고 하였다.

이러한 선행연구를 바탕으로 본 연구에서는 외식프랜차이 즈 기업의 서비스 가치와 태도 간의 관계를 분 석하기 위하 여 다음과 같은 가설을 설정하였다.

H1: 외식프랜차이즈의 서비스 가치는 인지적 태도에 정 $(+)$ 의 영향을 미칠 것이다.

H1-1: 품질 가치는 인지적 태도에 정(+)의 영향을 미칠 것 이다.

H1-2: 감정적 가치는 인지적 태도에 정(+)의 영향을 미칠 것이다.

H1-3: 경제적 가치는 인지적 태도에 정(+)의 영향을 미칠 것이다.

H1-4: 행동적 가치는 인지적 태도에 정(+)의 영향을 미칠 것이다.

H1-5: 평판 가치는 인지적 태도에 정(+)의 영향을 미칠 것 이다.

H2: 외식프랜차이즈의 서비스 가치는 정서적 태도에 정 $(+)$ 의 영향을 미칠 것이다.

H2-1: 품질 가치는 정서적 태도에 정(+)의 영향을 미칠 것
이다.

H2-2: 감정적 가치는 정서적 태도에 정(+)의 영향을 미칠 것이다.

H2-3: 경제적 가치는 정서적 태도에 정(+)의 영향을 미칠 것이다.

H2-4: 행동적 가치는 정서적 태도에 정(+)의 영향을 미칠 것이다.

H2-5: 평판 가치는 정서적 태도에 정(+)의 영향을 미칠 것 이다.

\subsection{2. 태도와 충성도 간의 관계}

태도와 충성도 간에는 긍정적인 관계가 있는 것으로 과거 부터 연구되어 왔다(Starr \& Rubinson, 1978). Keller(1993) 는 브랜드에 대한 지식은 태도를 형성시켜 충성도를 효과적 으로 파악할 수 있는 요인이라고 하였다.

태도는 행동을 포함한 다양한 행동 심리학 분야에서 행동 과 행동 의도를 유도하는 요인으로 연구되고 있다 (Morris, 2009). 태도는 직접적으로 관찰하거나 측정할 수 없는 심리 적 과정의 결과이지만, 사람들의 행동을 예 측할 수 있다 (Hunecke, Haustein, Böhler, \& Grischkat, 2010). 즉, 태도는 충성도를 예 측할 수 있는 요인이다(Faircloth, Capella, \& Alford, 2001).

이러한 선행연구를 바탕으로 본 연구에서는 외식프랜차이 즈 기업에 대한 태도와 충성도 간의 관계를 분 석하기 위하 여 다음과 같은 가설을 설정하였다.

H3: 인지적 태도는 충성도에 정 $(+)$ 의 영향을 미칠 것이다. H4: 정서적 태도는 충성도에 정 $(+)$ 의 영향을 미칠 것이다.

\section{2. 표본설계}

본 연구의 설문은 선행연구를 바탕으로 작성하여 온라인 설문조사 전문 기 관의 패 널을 대상으로 설문조사가 실시되 었다. 설문조사는 최근 1 개월 이내에 외식프랜차이즈 매장 을 방문한 경험이 있는 패 널을 대상으로 조사되었다. 설문조 사는 2019년 2월 13일부터 2월 19일까지 약 7일 동안 조사 되었으며, 300 명이 설문을 작성하였다. 총 300 명의 샘플 중 불성실한 설문 7 개를 제외한 293 개가 분 석에 이용되었다.

\section{3. 변수의 측정 및 정의}

본 연구에 사용된 변수는 7점 등간 척도가 이용되었으며, 외식프랜차이즈 기업에 대한 서비스 가치는 Petrick(2002)의 연구에서 사용된 서비스 가치를 본 연구의 상황에 맞게 수 정하여 품질 가치, 감정적 가치, 경제적 가치, 행동적 가치, 평판 가치의 5 가지 차원으로 구성되 었다. 품질 가치는 4 개 항목으로 측정되었으며, 외식프랜차이즈에 대한 믿음으로 정의되었다. 감정적 가치는 5 개 항목으로 측정되었으며, 외 식프랜차이즈에 대한 즐거움으로 정의되었다. 경제적 가치 는 5 개 항목으로 측정되었으며, 외식프랜차이즈에 대한 비 용 대비 성과로 정의되었다. 행동적 가치는 5 개 항목으로 
측정되었으며, 외식프랜차이즈 이용의 편리함으로 정의되었 다. 평판 가치는 5 개 항목으로 측정되었으며, 외식프랜차이 즈의 유명함으로 정의되었다.

태도는 Conner, Rhodes, Morris, McEachan, and Lawton (2011)의 연구에서 사용된 인지적 태도와 정서적 태도가 본 연구의 상황에 맞게 이용되 었으며, 인지적 태도는 5 개 항목, 정서적 태도는 4 개 항목으로 측정되었다. 인지적 태도는 외 식프랜차이즈 이용의 유용성으로 정의되었으며, 정서적 태 도는 외식프랜차이즈 이용의 긍정적 느낌으로 정의되었다. 마지막으로 충성도는 Zeithaml, Berry, and Parasuraman, (1996)의 연구를 본 연구의 상황에 맞게 수정하여 4개 항목 으로 측정되었으며, 외식프랜차이즈를 지속적으로 이용하려 는 의지로 정의되었다.

\section{4. 실증분석}

\section{1. 표본의 일반적 특성}

본 연구의 실증 분 석에 이용된 293명의 응답자에 대한 표본의 일반적 특성은 <Table 1>과 같다.

먼저, 성별은 여자 $(60.4 \%)$ 가 남자 $(39.6 \%)$ 에 비해 많았으 며, 결혼 유무는 기 혼(54.6\%)이 미 혼(45.4\%)보다 조 금 높은 것으로 나타났다. 연령대는 30 39세(55.3\%), 학력은 대 학교 재학 및 졸업 $(72.0 \%)$ 이 가장 많았다. 직업은 생산 기 술직 $(54.3 \%)$ 이 가장 높은 비중을 차지하였다.

Table 1: emographic Profile of the Respondents $(n=303)$

\begin{tabular}{|c|c|c|c|}
\hline & & $\mathbf{n}$ & $\%$ \\
\hline \multirow{2}{*}{ Gender } & Male & 116 & 39.6 \\
\hline & Female & 177 & 60.4 \\
\hline \multirow{2}{*}{ Marital status } & Single & 133 & 45.4 \\
\hline & Married & 160 & 54.6 \\
\hline \multirow{4}{*}{ Age } & $20-29$ & 53 & 18.1 \\
\hline & $30-39$ & 162 & 55.3 \\
\hline & $40-49$ & 77 & 26.3 \\
\hline & $50-59$ & 1 & 0.3 \\
\hline \multirow{4}{*}{$\begin{array}{l}\text { Educational } \\
\text { level }\end{array}$} & Below high school & 25 & 8.5 \\
\hline & Undergraduate & 31 & 10.6 \\
\hline & Four year university & 211 & 72.0 \\
\hline & Graduate school & 26 & 8.9 \\
\hline \multirow{7}{*}{ Job } & Student & 10 & 3.4 \\
\hline & Officer & 17 & 5.8 \\
\hline & Professional & 16 & 5.5 \\
\hline & Sales & 44 & 15.0 \\
\hline & Technical & 159 & 54.3 \\
\hline & Housewife & 11 & 3.8 \\
\hline & Others & 36 & 12.3 \\
\hline
\end{tabular}

\section{2. 측정모형 분석}

본 연구에 이용된 척도의 집중타당성과 판별타당성을 검 증하기 위한 확인적 요인분 석이 실시되 었다.

분석 결과, <Table 2>에서와 같이, 적합도 지수는 $\chi^{2}$ $=784.519\left(\mathrm{df}=436, \quad \chi^{2} / \mathrm{df}=1.799, \quad \mathrm{p}\right.$-value=0.000), $\quad \mathrm{CFI}=0.952$, $\mathrm{NFI}=0.899, \mathrm{GFI}=0.857, \mathrm{RMR}=0.065, \mathrm{RMSEA}=0.052$ 로 나타 나 구조 모형 분석 이용에 적합한 것으로 나타났다.

\section{3. 상관관계 분석}

집중타당성, 판별타당성 그리고 신뢰도 분 석 결과, 단일차 원성이 검증된 척도들의 방향과 상 관관계의 정도를 알아보 기 위해 상 관관계 분석을 실시한 결과, <Table 3>에서와 같 이, 연구가설에서 제시한 방향과 일치하는 것으로 나타났다.

\section{4. 연구모형의 검증}

본 연구에 이용된 외식프랜차이즈 기업의 서비스 가치, 인지적 태도, 정서적 태도, 그리고 충성도와 같은 연구 단위 들 간의 전체적 모형을 구조방정식 모형(SEM)으로 검증한 결과, 적합도는 $\chi^{2}=802.924\left(\mathrm{df}=441, \quad \chi^{2} / \mathrm{df}=1.821, \quad \mathrm{p}\right.$-value $=0.000), \mathrm{GFI}=0.854, \mathrm{NFI}=0.896, \mathrm{CFI}=0.950, \mathrm{RMR}=0.067$, $\mathrm{RMSEA}=0.053$ 으로 나타났다. 또한, 내생변수가 외생 변수에 의해서 설명되는 설명력 $\left(\mathrm{R}^{2}\right)$ 을 분 석한 결과, 인지적 태도는 $0.848(84.8 \%)$, 정서적 태도는 $0.819(81.9 \%)$, 그리고 충성도 는 $0.868(86.8 \%)$ 로 나타났다.

\section{5. 연구가설의 검증}

$\mathrm{H} 1$ 은 외식프랜차이즈 기업의 서비스 가치와 인지적 태도 간의 관계를 알아 보기위한 것이다. 먼저, 품질 가치가 인지 적 태도에 긍정적(+) 영향을 미 칠 것이라는 $\mathrm{H} 1-1$ 을 검증한 결과, 경로계수 값은 $-0.025, \mathrm{t}$ 값은 -0.181 로 품질 가치는 인 지적 태도에 통 계적으로 유의한 영향을 미치지 않는 것으로 나타났다( $p>0.05)$. 따라서 $\mathrm{H} 1-1$ 은 기각되었다. 다음으로 감정 가치가 인지적 태도에 긍정적(+) 영향을 미 칠 것이라는 $\mathrm{H} 1-2$ 를 검증한 결과, 경로계수 값은 0.220 , t값은 2.218 로 감정 가 치는 인지적 태도에 통 계적으로 유의한 정 $(+)$ 의 영향을 미치 는 것으로 나타났다 $(p<0.05)$. 따라서 H1-2는 채택되었다. 경 제적 가치가 인지적 태도에 긍정적(+) 영향을 미 칠 것이라는 $\mathrm{H} 1-3$ 을 검증한 결과, 경로계수 값은 0.190 , t값은 3.006 으로 경제적 가치는 인지적 태도에 통 계적으로 유의한 정 $(+)$ 의 영 향을 미치는 것으로 나타났다( $\mathrm{p}<0.01)$. 따라서 $\mathrm{H1} 1-3$ 은 채택되 었다. 행동 가치가 인지적 태도에 긍정적(+) 영향을 미 칠 것 이라는 $\mathrm{H} 1-4$ 를 검증한 결과, 경로계수 값은 0.036 , $\mathrm{t}$ 값은 0.588 로 행동 가치는 인지적 태도에 통 계적으로 유의한 영향 을 미치지 않는 것으로 나타났다 $(p>0.05)$. 
Table 2: Masurement Model $^{\mathrm{a}}$

\begin{tabular}{|c|c|c|c|c|}
\hline Items & $\begin{array}{c}\text { Standardized } \\
\text { factor loadings }\end{array}$ & $\mathrm{CCR}^{\mathrm{b}}$ & AVE $^{c}$ & $\begin{array}{c}\text { Cronbach } \\
\alpha\end{array}$ \\
\hline Quality value & & 0.639 & 0.872 & 0.876 \\
\hline This food-service franchise is great. & 0.863 & & & \\
\hline This food-service franchise can be reliable. & 0.814 & & & \\
\hline This food-service franchise keeps its promise. & 0.754 & & & \\
\hline This food-service franchise always provides the same quality. & 0.762 & & & \\
\hline Emotional value & & 0.686 & 0.894 & 0.896 \\
\hline \multicolumn{5}{|l|}{ This food-service franchise makes the visit feel better. } \\
\hline This food-service franchise is comfortable. & 0.796 & & & \\
\hline This food-service franchise is fun. & 0.855 & & & \\
\hline I am glad this food-service franchise. & 0.852 & & & \\
\hline This food-service franchise makes me happy. & 0.809 & & & \\
\hline Monetary value & & 0.710 & 0.879 & 0.902 \\
\hline \multicolumn{5}{|l|}{ This food-service franchise is good in price. } \\
\hline This food-service franchise is worth the money & 0.724 & & & \\
\hline This food-service franchise is fair in price. & 0.872 & & & \\
\hline The price of this food-service franchise was set at a reasonable level. & 0.904 & & & \\
\hline The price of this food-service franchise is economical. & 0.859 & & & \\
\hline Behavioral value & & 0.583 & 0.797 & 0.845 \\
\hline This food-service franchise is easy to visit. & 0.697 & & & \\
\hline This food-service franchise does not require energy to purchase. & 0.751 & & & \\
\hline This food-service franchise is easy to purchase. & 0.806 & & & \\
\hline This food-service franchise does not require effort to purchase. & 0.795 & & & \\
\hline This food-service franchise is not burdened. & - & & & \\
\hline Reputation value & & 0.619 & 0.890 & 0.890 \\
\hline This food-service franchise has a good reputation. & 0.734 & & & \\
\hline This food-service franchise is recognized. & 0.821 & & & \\
\hline This food-service franchise is great. & 0.783 & & & \\
\hline This food-service franchise is famous. & 0.776 & & & \\
\hline I like this food-service franchise. & 0.817 & & & \\
\hline Cognitive attitude & & 0.649 & 0.839 & 0.844 \\
\hline \multicolumn{5}{|l|}{ This food-service franchise is useful for our food life. } \\
\hline This food-service franchise is important. & 0.784 & & & \\
\hline \multicolumn{5}{|l|}{ This food-service franchise is worth it. } \\
\hline Use of this food-service franchise is rewarding. & 0.825 & & & \\
\hline This food-service franchise is beneficial. & 0.807 & & & \\
\hline Affective attitude & & 0.638 & 0.862 & 0.875 \\
\hline I am satisfied with this food-service franchise. & 0.782 & & & \\
\hline The use of this food-service franchise feels good. & 0.831 & & & \\
\hline It is pleasant to use this food-service franchise. & 0.797 & & & \\
\hline It is wonderful to use this food-service franchise. & 0.784 & & & \\
\hline $\begin{array}{l}\text { Loyalty } \\
\end{array}$ & & 0.704 & 0.878 & 0.903 \\
\hline I am planning to use this restaurant franchise in the future. & 0.841 & & & \\
\hline I am going to use this food-service franchise in the future. & 0.855 & & & \\
\hline I plan to use this food-service franchise more aggressively in the future. & 0.817 & & & \\
\hline I would recommend this food-service franchise to the people around me. & 0.842 & & & \\
\hline
\end{tabular}

${ }^{a} \chi^{2}=784.519\left(\mathrm{df}=436, \chi^{2} / \mathrm{df}=1.799, p\right.$-value=0.000), CFI=0.952, NFI=0.899, GFI=0.857, RMR=0.065, RMSEA=0.052

${ }^{b} \mathrm{CCR}$ (Composite construct reliability), ${ }^{\mathrm{C}} \mathrm{AVE}$ (Average variance extracted)

* Items were deleted during confirmatory factor analysis. 
Table 3: Construct Intercorrelations, Mean and Standard Deviation

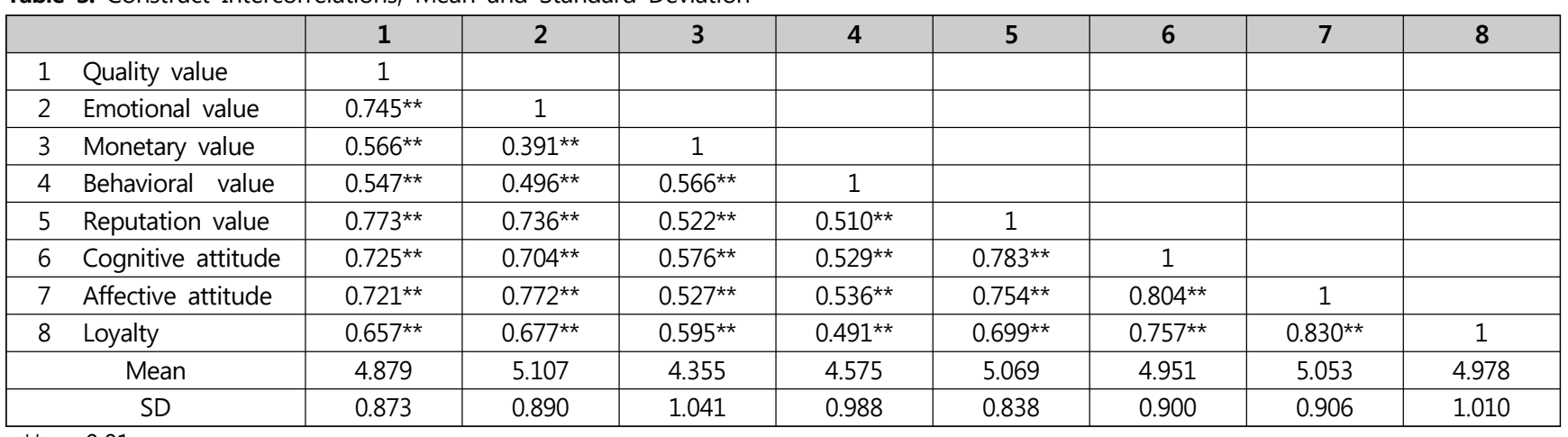

** $p<0.01$

Table 4: Standardized Parameter Estimates

\begin{tabular}{|c|c|c|c|c|c|c|}
\hline & \multicolumn{2}{|c|}{ Path } & Standardized coefficients & \multicolumn{2}{|c|}{ t-Value } & \\
\hline $\mathrm{H} 1-1$ & \multicolumn{2}{|c|}{ Quality value $\rightarrow$ Cognitive attitude } & -0.025 & -0.181 & 0.856 & Non-Supported \\
\hline $\mathrm{H} 1-2$ & \multicolumn{2}{|c|}{ Emotional value $\rightarrow$ Cognitive attitude } & 0.220 & 2.218 & * & Supported \\
\hline $\mathrm{H} 1-3$ & \multicolumn{2}{|c|}{ Monetary value $\rightarrow$ Cognitive attitude } & 0.190 & 3.006 & ** & Supported \\
\hline $\mathrm{H} 1-4$ & \multicolumn{2}{|c|}{ Behavioral value $\rightarrow$ Cognitive attitude } & 0.036 & 0.588 & 0.556 & Non-Supported \\
\hline $\mathrm{H} 1-5$ & \multicolumn{2}{|c|}{ Reputation value $\rightarrow$ Cognitive attitude } & 0.614 & 5.030 & $\star \star *$ & Supported \\
\hline $\mathrm{H} 2-1$ & \multicolumn{2}{|c|}{ Quality value $\rightarrow$ Affective attitude } & -0.099 & -0.780 & 0.436 & Non-Supported \\
\hline $\mathrm{H} 2-2$ & \multicolumn{2}{|c|}{ Emotional value $\rightarrow$ Affective attitude } & 0.535 & 5.381 & $\star \star$ & Supported \\
\hline $\mathrm{H} 2-3$ & \multicolumn{2}{|c|}{ Monetary value $\rightarrow$ Affective attitude } & 0.235 & 3.919 & ** & Supported \\
\hline $\mathrm{H} 2-4$ & \multicolumn{2}{|c|}{ Behavioral value $\rightarrow$ Affective attitude } & 0.015 & 0.268 & 0.788 & Non-Supported \\
\hline $\mathrm{H} 2-5$ & \multicolumn{2}{|c|}{ Reputation value $\rightarrow$ Affective attitude } & 0.353 & 3.253 & ** & Supported \\
\hline $\mathrm{H} 3$ & \multicolumn{2}{|c|}{ Cognitive attitude $\rightarrow$ Loyalty } & 0.052 & 0.346 & 0.729 & Non-Supported \\
\hline \multirow[t]{5}{*}{$\mathrm{H} 4$} & Affective at & $\rightarrow$ Loyalty & 0.883 & 5.527 & $\star \star *$ & Supported \\
\hline & \multicolumn{2}{|c|}{$R^{2}$} & \multicolumn{4}{|c|}{ Model fit } \\
\hline & Cognitive attitude & $0.848(84.8 \%)$ & \multicolumn{2}{|l|}{$x^{2}$} & \multicolumn{2}{|c|}{802.924} \\
\hline & Affective attitude & $0.819(81.9 \%)$ & \multicolumn{2}{|l|}{ d.f } & \multicolumn{2}{|r|}{441} \\
\hline & Loyalty & $0.868(86.8 \%)$ & \multicolumn{2}{|l|}{ p-value } & \multicolumn{2}{|c|}{0.000} \\
\hline
\end{tabular}

${ }^{* *} p<0.01 ;{ }^{*} p<0.05$

$\chi^{2}=802.924(\mathrm{df}=441, \chi 2 / d f=1.821, p$-value $=0.000), G F I=0.854, \mathrm{NFI}=0.896, \mathrm{CFI}=0.950, \mathrm{RMR}=0.067, \mathrm{RMSEA}=0.053$

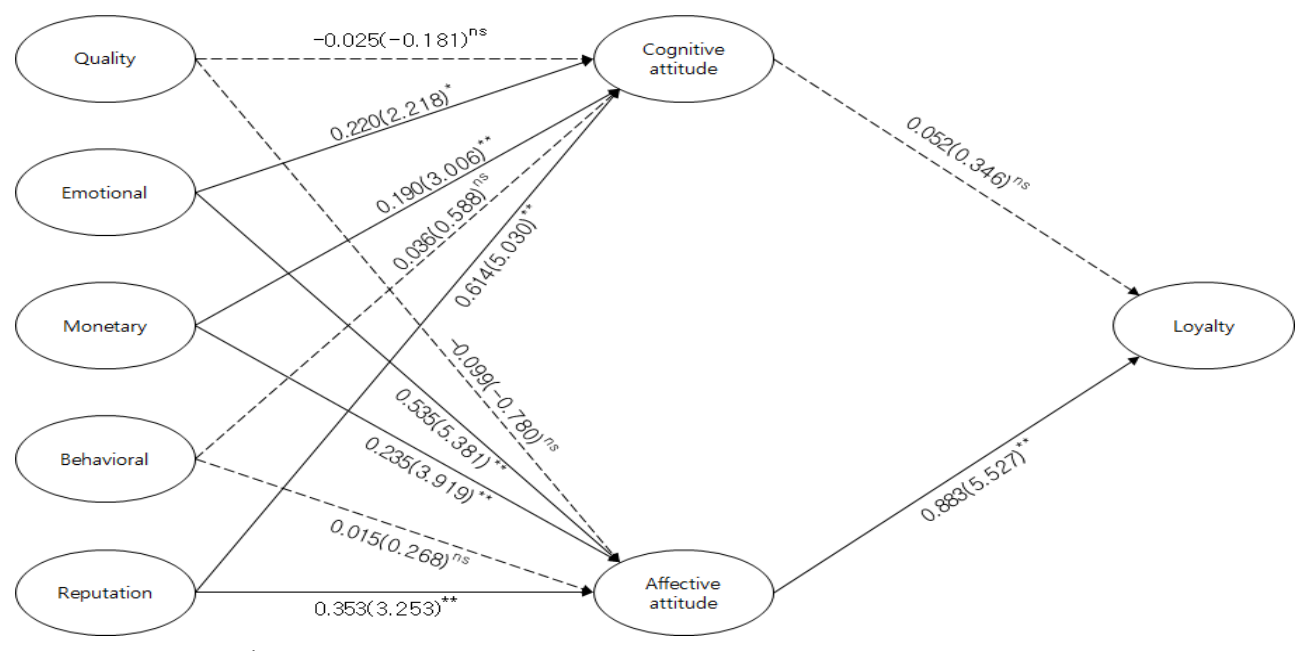

${ }^{*}=\mathrm{p}<0.01,{ }^{*}=\mathrm{p}<0.05, \mathrm{~ns}=$ non-supported

$\chi^{2}=802.924(\mathrm{df}=441, \chi 2 / \mathrm{df}=1.821, \mathrm{p}$-value=0.000), GFI=0.854, NFI=0.896, CFI=0.950, RMR=0.067, RMSEA=0.053

Figure 1: Estimates of the Structural Model 
따라서 H1-4는 기각되었다. 또한 평판 가치가 인지적 태 도에 긍정적(+) 영향을 미 칠 것이라는 $\mathrm{H} 1-5$ 를 검증한 결과 , 경로계수 값은 $0.614, \mathrm{t}$ 값은 5.030 으로 평판 가치는 인지적 태도에 통 계적으로 유의한 정 $(+)$ 의 영향을 미치는 것으로 나 타났다 $(p<0.01)$. 따라서 $\mathrm{H} 1-5$ 는 채택되었다.

$\mathrm{H} 2$ 는 외식프랜차이즈 기업의 서비스 가치와 정서적 태도 간의 관계를 알아 보기위한 것이다. 먼저, 품질 가치가 정서 적 태도에 긍정적(+) 영향을 미 칠 것이라는 $\mathrm{H} 2-1$ 을 검증한 결과, 경로계수 값은 -0.099 , t값은 -0.780 로 품질 가치는 정 서적 태도에 통 계적으로 유의한 영향을 미치지 않는 것으로 나타났다( $\mathrm{p}>0.05)$. 따라서 $\mathrm{H} 2-1$ 은 기각되었다. 다음으로 감 정 가치가 정서적 태도에 긍정적(+) 영향을 미 칠 것이라는 $\mathrm{H} 2-2$ 를 검증한 결과, 경로계수 값은 0.535 , t값은 5.381로 감정 가치는 정서적 태도에 통 계적으로 유의한 정 (+)의 영향 을 미치는 것으로 나타났다 $(\mathrm{p}<0.01)$. 따라서 $\mathrm{H} 2-2$ 는 채택되 었다. 경제적 가치가 정서적 태도에 긍정적(+) 영향을 미 칠 것이라는 $\mathrm{H} 2-3$ 을 검증한 결과, 경로계수 값은 0.235 , $\mathrm{t}$ 값은 3.919로 경제적 가치는 정서적 태도에 통 계적으로 유의한 정 $(+)$ 의 영향을 미치는 것으로 나타났다 $(\mathrm{p}<0.01)$. 따라서 $\mathrm{H} 2-3$ 은 채택되었다. 행동 가치가 정서적 태도에 긍정적(+) 영향을 미 칠 것이라는 $\mathrm{H} 2-4$ 를 검증한 결과, 경로계수 값은 0.015 , t값은 0.268 로 행동 가치는 정서적 태도에 통 계적으 로 유의한 영향을 미치지 않는 것으로 나타났다( $p>0.05)$. 따 라서 $\mathrm{H} 2-4$ 는 기각되었다. 또한 평판 가치가 정서적 태도에 긍정적(+) 영향을 미 칠 것이라는 $\mathrm{H} 2-5$ 를 검증한 결과, 경로 계수 값은 0.353 , t값은 3.253 으로 평판 가치는 정서적 태도 에 통 계적으로 유의한 정 $(+)$ 의 영향을 미치는 것으로 나타났 다(p<0.01). 따라서 $\mathrm{H} 2-5$ 는 채택되었다.

$\mathrm{H} 3$ 은 인지적 태도와 충성도 간의 관계를 알아 보기위한 것이다. 인지적 태도가 충성도에 긍정적(+) 영향을 미 칠 것이 라는 $\mathrm{H} 3$ 을 검증한 결과, 경로계수 값은 0.052 , t값은 0.346 으 로 인지적 태도는 충성도에 통 계적으로 유의한 영향을 미치 는 것으로 나타났다( $p>0.05)$. 따라서 $\mathrm{H} 3$ 은 기각되었다.

$\mathrm{H} 4$ 는 정서적 태도와 충성도 간의 관계를 알아 보기위한 것이다. 정서적 태도가 충성도에 긍정적(+) 영향을 미 칠 것 이라는 $\mathrm{H} 4$ 를 검증한 결과, 경로계수 값은 0.883 , t값은 5.527 로 인지적 태도는 충성도에 통 계적으로 유의한 영향을 미치는 것으로 나타났다( $p<0.01)$. 따라서 $\mathrm{H} 4$ 는 채택되었다.

\section{5. 결론}

본 연구는 외식프랜차이즈 기업의 서비스 전 략을 수 립하 기 위해 품질, 감정, 경제적, 행동, 그리고 평판으로 구성된 서비스 가치가 인지적 태도와 정서적 태도에 미치는 영향을 파악하고 인지적 태도와 정서적 태도가 충성도에 미치는 영 향을 파악하였다. 분석 결과 감정, 경제적, 그리고 평판 가 치는 인지적 태도와 정서적 태도에 정 (+)의 영향을 미치는 것으로 나타났으나, 품질 가치와 행동 가치는 인지적 태도와 정서적 태도에 유의한 영향을 미치지 않는 것으로 나타났다. 또한, 정서적 가치는 충성도에 정 $(+)$ 의 영향을 미치는 것으
로 나타났으나, 인지적 태도는 충성도에 유의한 영향을 미치 지 않는 것으로 나타났다.

이러한 연구결과에 따른 이론적 시사점은 다음과 같다.

첫째, 본 연구에 사용된 외식프랜차이즈 기업에 대한 서 비스 가치 중 감정, 경제적, 그리고 평판 가치가 인지적 태 도와 정서적 태도에 긍정적인 영향을 미치는 것으로 나타났 다. 이러한 결과는 고 객의 경험적 가치가 태도를 통해 행동 의도에 영향을 미치는 구조인 가치 -태도-행동(Honkanen et al., 2006) 구조를 지지한다. 또한, 미적, 서비스, 우수성, 그 리고 즐거움이 포함된 경험적 가치가 태도에 긍정적 영향을 미친다고 연구한 Keng and Ting(2009)의 연구와 비 슷한 결 과로 나타났다.

둘째, 품질과 행동적 가치는 인지적 태도와 정서적 태도 에 유의한 영향을 미치지 않는 것으로 나타났다. 이러한 결 과는 인지적 태도가 대상에 대한 유용성 평가라고 연구한 Celebi(2015)와 다르게 나타났다. 또한 정서적 태도가 대상 에 대한 경험의 결과라고 연구한(Fiore \& Kim, 2007)의 연 구와 다르게 나타났다. 이러한 이유는 외식프랜차이즈의 특 징 때문일 수 있다. 일반적으로 외식프랜차이즈는 대중적인 메뉴를 대중적인 서비스로 제공하기 때문일 수 있다. 즉, 고 품질의 서비스 가치를 요구하지 않기 때문일 것이다.

셋째, 정서적 태도는 충성도에 긍정적인 영향을 미치는 것으로 나타났으나, 인지적 태도는 충성도에 유의한 영향을 미치지 않는 것으로 나타났다. 이러한 결과는 행동 의도에 정서적 태도가 인지적 태도보다 더 강한 영향을 미치는 연 구와 비 슷한 결과로 나타났다(Glasman \& Albarracin, 2006; Kraft, Rise, Sutton \& Roysamb, 2005; Trafimow et al., 2004). 그러나 이러한 연구들도 인지적 태도가 행동의도에 영향을 미치는 것으로 나타나, 본 연구 결과와 다 른 결과로 볼 수 있다. 이러한 이유는 많은 고 객들이 외식프랜차이즈 매장을 식사하는 장소뿐만 아니라 모임이나 회식 장소로 이 용하기 때문일 것이다.

본 연구의 실 무적 시사점은 다음과 같다.

첫째, 외식프랜차이즈 기업은 고 객이 매장을 편하게 이용 할 수 있는 서비스를 개발해야 한다. 서비스 가치의 포괄적 구성 요소는 무형뿐만 아니라 유 형의 메뉴 및 환경(인테리 어, 익스테리어, 매장 위치 등)을 포함하고 있다. 즉, 고객이 편하게 이용할 수 있는 환경을 개발하고 무형의 서비스를 제공해야 한다.

둘째, 외식프랜차이즈 기업은 합리적인 가 격의 서비스를 제공해야 한다. 외식프랜차이즈는 대중적인 메뉴를 대중적 인 서비스를 대량 생산 후에 대량으로 판매할 수 있다. 메뉴 나 서비스의 가 격이 높으면 목표 시장의 규모가 작기 때문 에 대량 생산, 대량 판매를 할 수 없다. 따라서 외식프랜차 이즈 기업은 고 품질의 메뉴를 합리적인 가 격으로 대량으로 판매하여 이 익을 창출할 필요가 있다.

셋째, 외식프랜차이즈 기업은 고 객의 평판에 전 략적으로 대응할 필요가 있다. 대중 매체가 아 닌 개인이 정보를 생산 하고 확산시킬 수 있는 플랫폼이 개발되어 과거와 달리 정 보가 빠르게 확산되고 있다. 또한 최근에는 외식프랜차이즈 기업의 평판으로 성장하거나, 시장에서 퇴출하는 기업이 나 
타나고 있다. 즉, 외식프랜차이즈 기업은 고 객의 평판을 지 속적으로 모니터링 하여 시장 상황에 적절히 대응할 필요가 있다.

넷째, 외식프랜차이즈 기업은 고 객과의 정서적 상호작용 이 가능한 서비스 방 법을 개발할 필요가 있다. 외식프랜차이 즈는 메뉴만 제공하는 기업이 아 닌 서비스도 판매하는 업종 이라고 할 수 있다. 따라서 외식프랜차이즈 기업은 고 객과 정서적으로 상호작용할 수 있는 지속적인 서비스 방 법을 개 발하고 직원에게 교육할 필요가 있다.

마지막으로 본 연구에서 서비스 가치는 일반적인 서비스 가치로 개발된 품질, 감정, 경제적, 구매, 그리고 평판으로 구성하였다. 외식프랜차이즈는 커피 전문점, 패스트푸드, 배 달 전문점, 한식, 중식, 양식 등 다양한 업종으로 구성되어 있다. 즉, 본 연구에서는 다양한 업종의 서비스 가치를 포괄 적으로 연구하였다. 따라서 향 후 연구에서는 각 업종에 맞는 외식프랜차이즈 서비스 가치를 개발하여 연구할 필요가 있 다.

\section{References}

Abdul-Muhmin, A. G. (2010). Repeat purchase intentions in online shopping: The role of satisfaction, attitude, and online retailers' performance. Journal of International Consumer Marketing, 23(1), 5-20.

Ajzen, I., \& Fishbein, M. (1977). Attitude-behavior relations: A theoretical analysis and review of empirical research. Psychological Bulletin, 84(5), 888-918.

Bagozzi, R. P., Gopinath, M., \& Nyer, P. U. (1999). The role of emotions in marketing. Journal of the Academy of Marketing Science, 27(2), 184-206.

Baldinger, A. L., \& Rubinson, J. (1996). Brand loyalty: The link between attitude and behavior. Journal of Advertising Research, 36(6), 22-35.

Baloglu, S. (2002). Dimensions of customer loyalty: Separating friends from well wishers. Cornell Hotel and Restaurant Administration Quarterly, 43(1), 47-59.

Beatty, S. E., Homer, P., \& Kahle, L. R. (1988). The involvement-commitment model: Theory and implications. Journal of Business Research, 16(2), 149-167.

Birgelen, M. V., Ruyter, K. D., \& Wetzels, M. (2003). The impact of attitude strength on customer-oriented priority setting by decision-makers: An empirical investigation. Journal of Economic Psychology, 24(6), 763-783.

Bojanic, D. C. (1996). Consumer perceptions of price, value and satisfaction in the hotel industry: An exploratory study. Journal of Hospitality \& Leisure Marketing, 4(1), 5-22.

Boulding, W., Kalra, A., Staelin, R., \& Zeithaml, V. A. (1993). A dynamic process model of service quality: From expectations to behavioral intentions. Journal of Marketing Research, 30(1), 7-27.
Celebi, S. I. (2015). How do motives affect attitudes and behaviors toward internet advertising and Facebook advertising?. Computers in Human Behavior, 51, 312-324.

Cheng, S. (2011). Comparisons of competing models between attitudinal loyalty and behavioral loyalty. International Journal of Business and Social Science, 2(10), 149-166.

Chudry, F., Foxall, G., \& Pallister, J. (2011). Exploring attitudes and predicting intentions: Profiling student debtors using an extended theory of planned behavior. Journal of Applied Social Psychology, 41(1), 119-149.

Conner, M., Rhodes, R. E., Morris, B., McEachan, R., \& Lawton, R. (2011). Changing exercise through targeting affective or cognitive attitudes. Psychology and Health, 26(2), 133-149.

Cronin Jr, J. J., \& Taylor, S. A. (1992). Measuring service quality: A reexamination and extension. Journal of Marketing, 56(3), 55-68.

Cronin Jr, J. J., \& Taylor, S. A. (1994). SERVPERF versus SERVQUAL: Reconciling performance-based and perceptions-minus-expectations measurement of service quality. Journal of Marketing, 58(1), 125-131.

Desai, K. K., \& Mahajan, V. (1998). Strategic role of affect-based attitudes in the acquisition, development, and retention of customers. Journal of Business Research, 42(3), 309-324.

De Ruyter, K., Bloemer, J., \& Peeters, P. (1997). Merging service quality and service satisfaction. An empirical test of an integrative model. Journal of Economic Psychology, 18(4), 387-406.

Dick, A. S., \& Basu, K. (1994). Customer loyalty: Toward an integrated conceptual framework. Journal of the Academy of Marketing Science, 22(2), 99-113.

Dodds, W. B., Monroe, K. B., \& Grewal, D. (1991). Effects of price, brand, and store information on buyers' product evaluations. Journal of Marketing Research, 28(3), 307-319.

Douglas, L., \& Connor, R. (2003). Attitudes to service quality-the expectation gap. Nutrition \& Food Science, 33(4), 165-172.

Eberl, M., \& Schwaiger, M. (2005). Corporate reputation: Disentangling the effects on financial performance. European Journal of Marketing, 39(7/8), 838-854.

Faircloth, J. B., Capella, L. M., \& Alford, B. L. (2001). The effect of brand attitude and brand image on brand equity. Journal of Marketing Theory and Practice, 9(3), 61-75.

Farris, P. W., Bendle, N., Pfeifer, P., \& Reibstein, D. (2010). Marketing metrics: The definitive guide to measuring marketing performance. Pearson Education.

Fiore, A. M., \& Kim, J. (2007). An integrative framework capturing experiential and utilitarian shopping experience. International Journal of Retail \& Distribution Management, 35(6), 421-442. 
Fornell, C., Mithas, S., Morgeson III, F. V., \& Krishnan, M. S. (2006). Customer satisfaction and stock prices: High returns, low risk. Journal of Marketing, 70(1), 3-14.

Giner-Sorolla, R. (2001). Guilty pleasures and grim necessities: Affective attitudes in dilemmas of self-control. Journal of Personality and Social Psychology, 80(2), 206-221.

Glasman, L. R., \& Albarracin, D. (2006). Forming attitudes that predict future behavior: A meta-analysis of the attitude-behavior relation. Psychological Bulletin, 132(5), 778-822.

Grönroos, C. (1984). A service quality model and its marketing implications. European Journal of Marketing, 18(4), 36-44.

Gustafsson, A., Nilsson, L., \& Johnson, M. D. (2003). The role of quality practices in service organizations. International Journal of Service Industry Management, 14(2), 232-244.

Hasan, B. (2010). Exploring gender differences in online shopping attitude. Computers in Human Behavior, 26(4), 597-601.

Honkanen, P., Verplanken, B., \& Olsen, S. O. (2006). Ethical values and motives driving organic food choice. Journal of Consumer Behaviour: An International Research Review, 5(5), 420-430.

Hu, H. H., Kandampully, J., \& Juwaheer, T. D. (2009). Relationships and impacts of service quality, perceived value, customer satisfaction, and image: An empirical study. The Service Industries Journal, 29(2), 111-125.

Hunecke, M., Haustein, S., Böhler, S., \& Grischkat, S. (2010). Attitude-based target groups to reduce the ecological impact of daily mobility behavior. Environment and Behavior, 42(1), 3-43.

Kandampully, J., \& Suhartanto, D. (2000). Customer loyalty in the hotel industry: The role of customer satisfaction and image. International Journal of Contemporary Hospitality Management, 12(6), 346-351.

Karmarkar, U. (2004). Will you survive the services revolution?. Harvard Business Review, 82(6), 100-107.

Keller, K. L. (1993). Conceptualizing, measuring, and managing customer-based brand equity. Journal of Marketing, 57(1), 1-22.

Keng, C. J., \& Ting, H. Y. (2009). The acceptance of blogs: Using a customer experiential value perspective. Internet Research, 19(5), 479-495.

Keng, C. J., Huang, T. L., Zheng, L. J., \& Hsu, M. K. (2007). Modeling service encounters and customer experiential value in retailing: An empirical investigation of shopping mall customers in Taiwan. International Journal of Service Industry Management, 18(4), 349-367.

Kraft, P., Rise, J., Sutton, S., \& Røysamb, E. (2005). Perceived difficulty in the theory of planned behaviour: Perceived behavioural control or affective attitude?
British Journal of Social Psychology, 44(3), 479-496.

Kumar, A., Lee, H. J., \& Kim, Y. K. (2009). Indian consumers' purchase intention toward a United States versus local brand. Journal of Business Research, 62(5), 521-527.

Kursunluoglu, E. (2011). Customer service effects on customer satisfaction and customer loyalty: A field research in shopping centers in Izmir City-Turkey. International Journal of Business and Social Science, 2(17), 52-59.

Lai, F., Griffin, M., \& Babin, B. J. (2009). How quality, value, image, and satisfaction create loyalty at a Chinese telecom. Journal of Business Research, 62(10), 980-986.

Lawton, R., Conner, M., \& McEachan, R. (2009). Desire or reason: Predicting health behaviors from affective and cognitive attitudes. Health Psychology, 28(1), 56-65.

Lin, C. H., Sher, P. J., \& Shih, H. Y. (2005). Past progress and future directions in conceptualizing customer perceived value. International Journal of Service Industry Management, 16(4), 318-336.

Lovelock, C. (2000). Functional integration in services. Handbook of Services Marketing \& Management', Sage, Thousand Oaks.

Majumdar, A. (2005). A model for customer loyalty for retail stores inside shopping malls-an Indian perspective. Journal of Services Research, 27(1), 5-21.

Malhotra, N. K. (2005). Attitude and affect: New frontiers of research in the 21st century. Journal of Business Research, 58(4), 477-482.

Meyer, C., \& Schwager, A. (2007). Understanding customer experience. Harvard Business Review, 85(2), 116-126.

Moon, M. A., Khalid, M. J., Awan, H. M., Attiq, S., Rasool, H., \& Kiran, M. (2017). Consumer's perceptions of website's utilitarian and hedonic attributes and online purchase intentions: A cognitive-affective attitude approach. Spanish Journal of Marketing-ESIC, 21(2), 73-88.

Morris, J. S. (2009). The Daily Show with Jon Stewart and audience attitude change during the 2004 party conventions. Political Behavior, 31(1), 79-102.

Nambisan, S., \& Baron, R. A. (2007). Interactions in virtual customer environments: Implications for product support and customer relationship management. Journal of Interactive Marketing, 21(2), 42-62.

Parasuraman, A., \& Grewal, D. (2000). The impact of technology on the quality-value-loyalty chain: A research agenda. Journal of the Academy of Marketing Science, 28(1), 168-174.

Parasuraman, A., Zeithaml, V. A., \& Berry, L. L. (1988). Servqual: A multiple-item scale for measuring consumer perceptions of service quality. Journal of Retailing, 64(1), 12-40. 
Petrick, J. F. (2002). Development of a multi-dimensional scale for measuring the perceived value of a service. Journal of Leisure Research, 34(2), 119-134.

Petrick, J. F., \& Backman, S. J. (2002). An examination of the construct of perceived value for the prediction of golf travelers' intentions to revisit. Journal of Travel Research, 41(1), 38-45.

Pine, B. J., \& Gilmore, J. H. (1998). Welcome to the experience economy. Harvard Business Review, 76, 97-105.

Reid, R. D., \& Sandler, M. (1992). The use of technology to improve service quality: A look at the extent of service improvements to be gained through investments in technology and expanded facilities and programs. Cornell Hotel and Restaurant Administration Quarterly, 33(3), 68-73.

Ruiz, D. M., Gremler, D. D., Washburn, J. H., \& Carrión, G. C. (2008). Service value revisited: Specifying a higher-order, formative measure. Journal of Business Research, 61(12), 1278-1291.

Ruth, J. A., \& York, A. (2004). Framing information to enhance corporate reputation: The impact of message source, information type, and reference point. Journal of Business Research, 57(1), 14-20.

Sallam, M. A. A., \& Wahid, N. A. (2012). Endorser credibility effects on Yemeni male consumer's attitudes towards advertising, brand attitude and purchase intention: The mediating role of attitude toward brand. International Business Research, 5(4), 55-66.

Sánchez-Fernández, R., Iniesta-Bonillo, M. Á., \& Holbrook, M. B. (2009). The conceptualisation and measurement of consumer value in services. International Journal of Market Research, 51(1), 1-17.

Schwartz, S. H. (1994). Are there universal aspects in the structure and contents of human values?. Journal of Social Issues, 50(4), 19-45.

Sheth, J. N., Newman, B. I., \& Gross, B. L. (1991). Why we buy what we buy: A theory of consumption values. Journal of Business Research, 22(2), 159-170.

Shih, H. P., Lai, K. H., \& Cheng, T. C. E. (2013). Informational and relational influences on electronic word of mouth: An empirical study of an online consumer discussion forum. International Journal of Electronic Commerce, 17(4), 137-166.

Simester, D. (2016). Why great new products fail: Many innovative new products don't succeed in the marketplace. One common reason: Companies don't focus enough on understanding how customers evaluate products and make purchase decisions. MIT Sloan Manage Rev, 57(3), 32-39.

Starr, M. K., \& Rubinson, J. R. (1978). A loyalty group segmentation model for brand purchasing simulation. Journal of Marketing Research, 15(3), 378-383.

Sweeney, J. C., \& Soutar, G. N. (2001). Consumer perceived value: The development of a multiple item scale. Journal of Retailing, 77(2), 203-220.

Trafimow, D., Sheeran, P., Lombardo, B., Finlay, K. A., Brown, J., \& Armitage, C. J. (2004). Affective and cognitive control of persons and behaviours. British Journal of Social Psychology, 43(2), 207-224.

Tudoran, A., Olsen, S. O., \& Dopico, D. C. (2009). The effect of health benefit information on consumers health value, attitudes and intentions. Appetite, 52(3), 568-579.

Vargo, S. L., \& Lusch, R. F. (2008). Service-dominant logic: Continuing the evolution. Journal of the Academy of Marketing Science, 36(1), 1-10.

Vaske, J. J., \& Donnelly, M. P. (1999). A value-attitudebehavior model predicting wildland preservation voting intentions. Society \& Natural Resources, 12(6), 523-537.

Vermeir, I., \& Verbeke, W. (2008). Sustainable food consumption among young adults in Belgium: Theory of planned behaviour and the role of confidence and values. Ecological Economics, 64(3), 542-553.

Weigelt, K., \& Camerer, C. (1988). Reputation and corporate strategy: A review of recent theory and applications. Strategic Management Journal, 9(5), 443-454.

Williams Jr, R. M. (1979). Change and stability in values and value systems: $A$ sociological perspective. Understanding human values. New York, NY: Free Press.

Yang, Y., Liu, X., Jing, F., \& Li, J. (2014). How does perceived value affect travelers' satisfaction and loyalty?. Social Behavior and Personality: An International Journal, 42(10), 1733-1744.

Zeithaml, V. A. (1988). Consumer perceptions of price, quality, and value: A means-end model and synthesis of evidence. Journal of Marketing, 52(3), 2-22.

Zeithaml, V. A., Berry, L. L., \& Parasuraman, A. (1996). The behavioral consequences of service quality. Journal of Marketing, 60(2), 31-46.

Zhang, B., \& Kim, J. H. (2013). Luxury fashion consumption in China: Factors affecting attitude and purchase intent. Journal of Retailing and Consumer Services, 20(1), 68-79. 